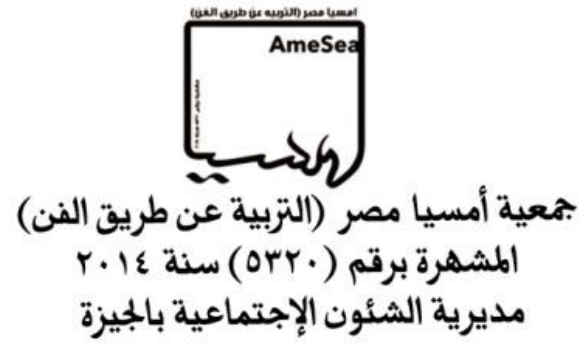

تقويم مهارات عزف السلالم الموسيقية على آلة البيانوبالكليات المتضصصة

\title{
في التربية الموسيقية
}

Evaluation of playing the piano scales skills on specialized musical education colleges

إعداد

استاذ دكتور ذجوى ابو النصر

كلية التربية الموسيقية - جامعة حلوان

جمهورية مصر العربية 


\section{تقويم مهارات عزف السلالم الموسيقية على آلة البيانو بالكليات المتخصصة في التربية الموسيقية

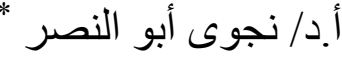

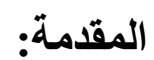

تؤكد الاتجاهات التربوية المعاصرة الحاجة إلى نظام تتحقق فيه الجودة الثناملة لزيادة الكفاءة

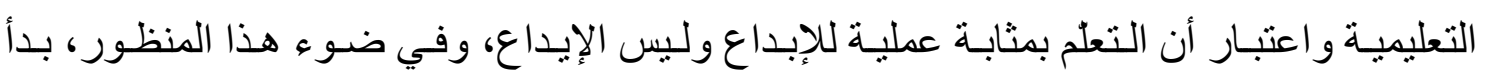

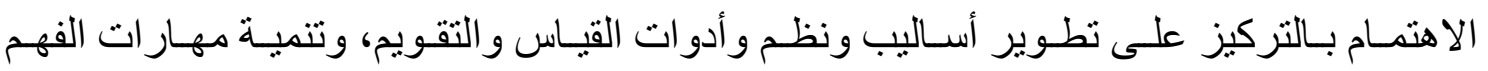

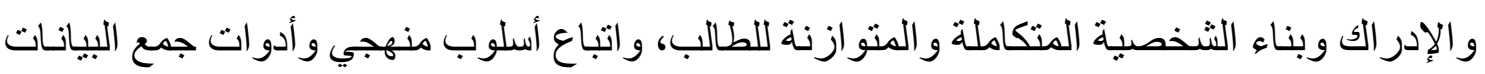
لتحديد مدى فعالية العلاقة بين مخرجات التعلم وبين عناصر محتوى المقرر اته، كمدخل حقيقي

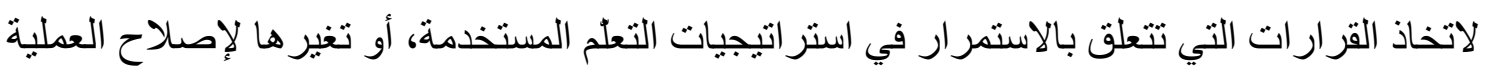

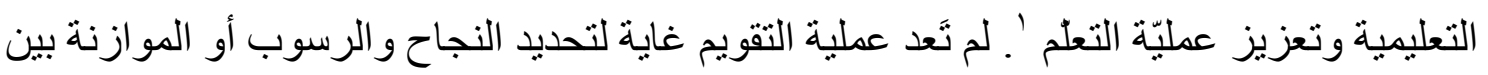

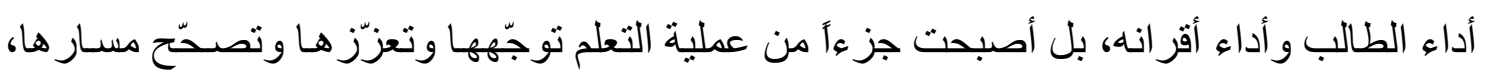
من خلال متابعه دقيقة للمدخلات و المخرجات المستهدفة من العملية التعليمية ` ، واستخدام أسـاليب ونظم لنرجمة النشاط الذاتي و المجود الثخصي الصادر عن الطالب بصورة مستمرّة ،.

تعرض هذه الورقة مؤشر ات القياس و التقويم اللازمة لتحقيق مخرجات التعلم المستهدفة من عزف التف

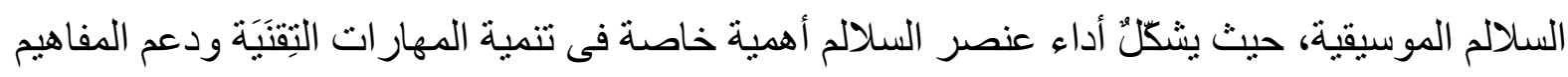

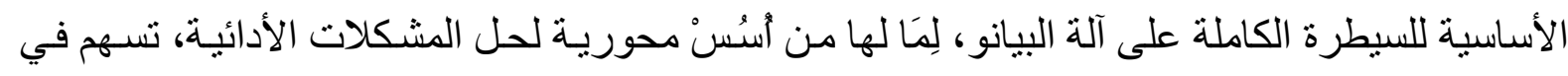

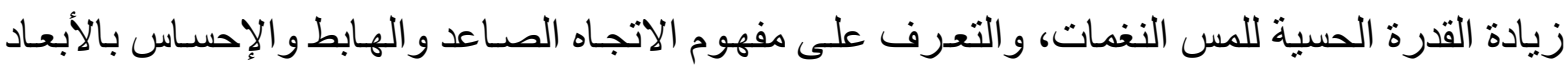

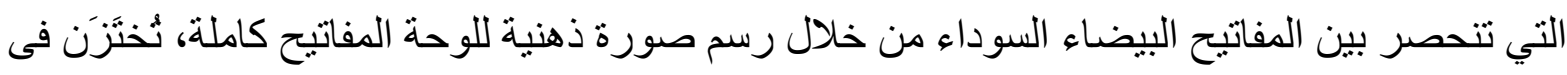

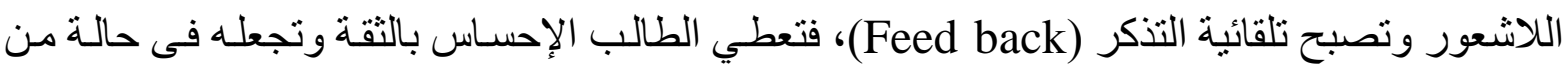

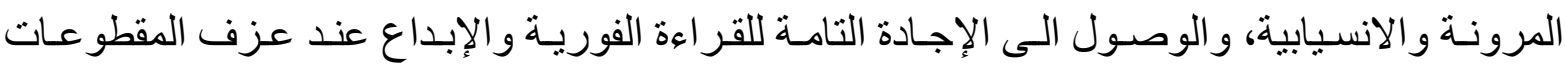
و الدراسات بمحتوى المقرر الدراسي دون النظر الى لوحة المفاتيح .

* نجوى فؤاد أبو النصر : أستاذ دكتور بقسم الأداء ـ شعبة البيانو ، كلية التربية الموسيقية ، جامعة حلوان.

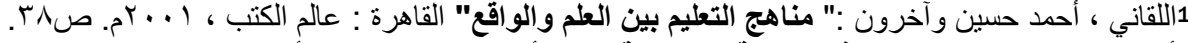

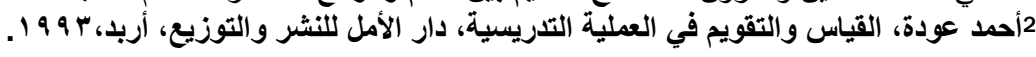

(AmeSea Database - me -January- April. 2018- 0344) 


\section{أسباب ضعف الطلاب في مهارة أداء السلالم:}

• تدني الدافعية لدى الطلبة، وهي سمة تؤثر سلباً على نحو عام في كل الجو انب الأكاديمية،

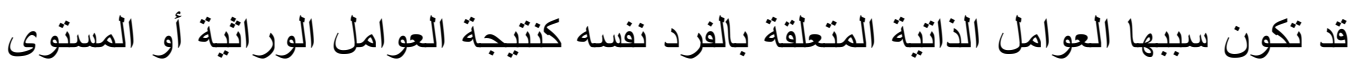

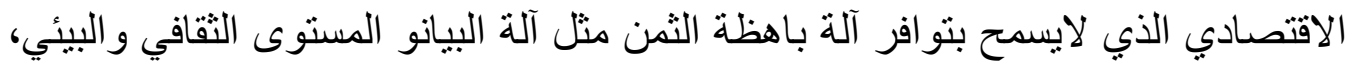

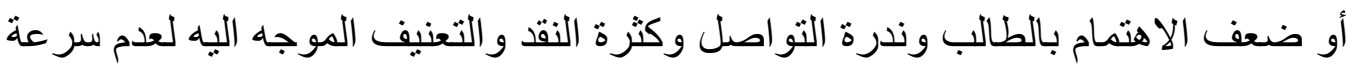

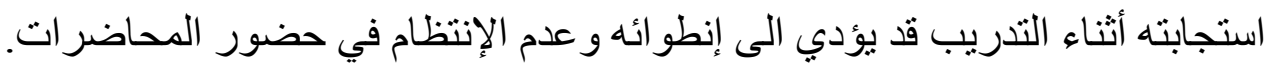
أساليب التعلم التي تعتمد على الحفظ و التلقين، حيث يعتمد الطالب في تعلم عزف السلّم

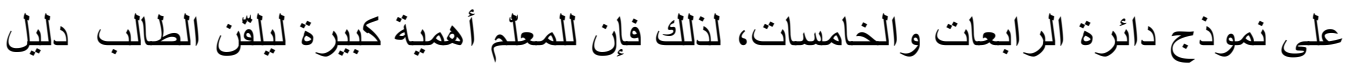

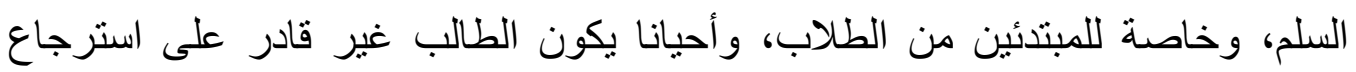

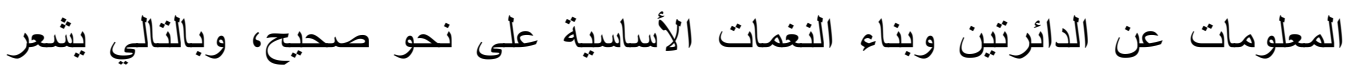
بالإحباط وأحيانا يصل الأمر الى بناء فجوة كبيرة بين ما يسترجعه من معلومات وبل وبين الوصول الى أسلوب الأداء الصحيح.

سوء التدريب الذي ينتج عنه أخطاء شائعه كالتصاق الأصابع بالمفاتيح أو تحميل الأصبع الخامس

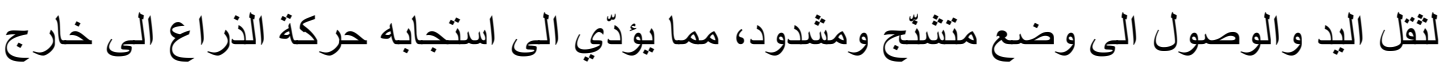

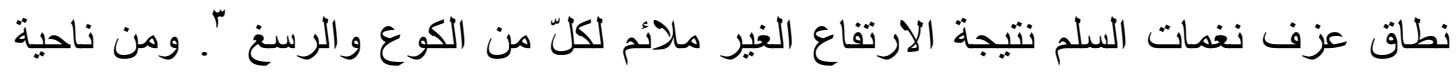

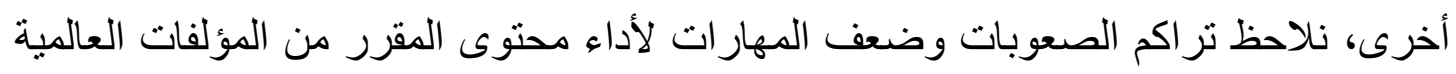
و الدر اسات، و البعض منهم يستغرق وقتا أطول أثناء القر اءة الفورية مقارنة مع زملائه الآخرين. • محتوى المقرر وما يتضمّنه من عزف السلم الكبير والصغير المناسب مما قد يتسبب

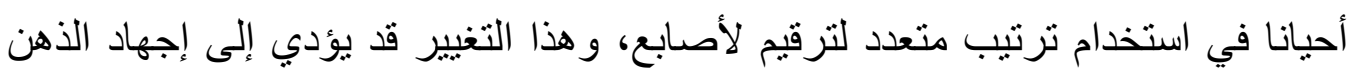
و التشتيت وزيادة التعقيد.

\section{لمعالجة هذا الضعف ينصح بتنفيذ ما يأتي:}

• دراسة أسباب تدنّي دافعية النتعلم ومعالجتها، على سبيل المثال، تدني الدافعية نتيجة لعوامل

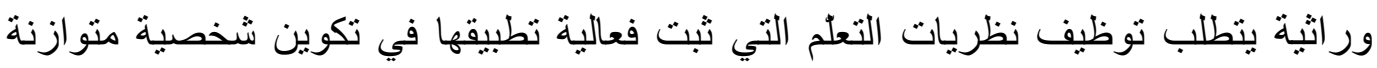

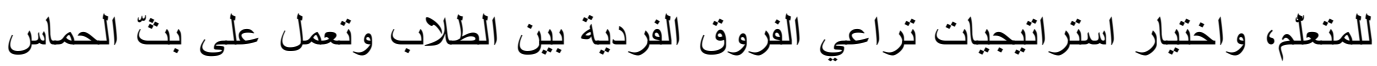
و الرغبة في تتمية المهارات و الخبر ات لزيادة عنصري الكفاءة و الفاعلية . 
إعادة ترتيب عزف السلالم بمحتوى المقرر، ومراعاة أن الطالب المبتدئ بربط صورة

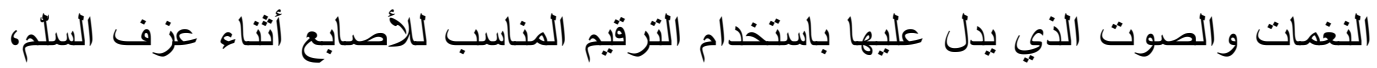
ولذلك ، فإن عزف السلم الكبير والصغير المباثر (الهارموني ـ الميلودي ) باستخدام نفس الهـ ترقيم الأصابع يزيد من سرعة الاستجابة للمؤثرات المرئية، واستثارة قوى المتعلم الذهنية

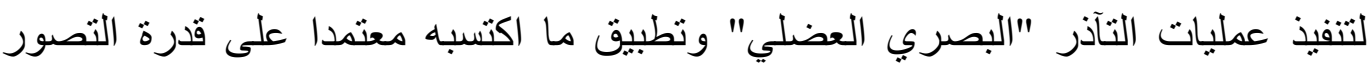
و التخيل "Imagination" وتداعي المعاني وتحقيق الاستبصار.

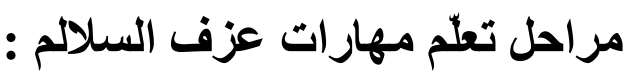

المرحلة الأولى : وضع الجسم على لوحة المفاتيح ، وتثمل: الوضع الطبيعي لليد : ويؤخذ من الوضع الطبيعي لحركة الذراع حين يتحرّك من الكتف أثناء الوقوف مثل بندول الساعة ، عندئذ يتعلم العازف كيف يحتفظ بعضلات الذراع فيعى في حالة

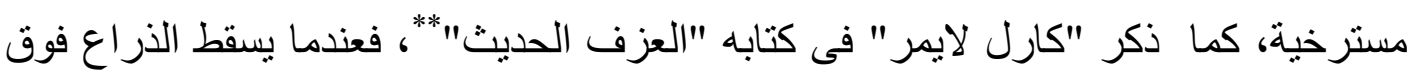
لوحة المفاتيح تكون اليد فى وضع انسيابي منحنى فى استدارة (الأطر اف إلى أسفل والإبهام

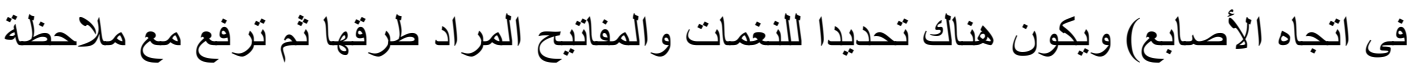

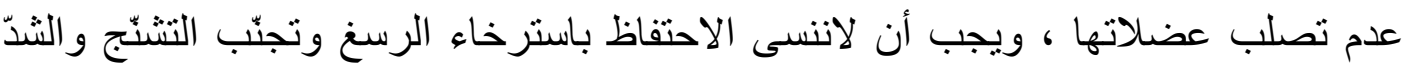
لعضلات اليد. الجلسة الصحيحة : إن القاعدة الأساسية فى العزف يكون أساسها توازن الجذع وحرية الحركة

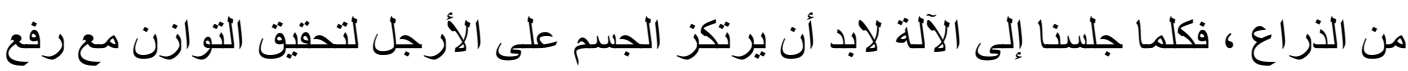

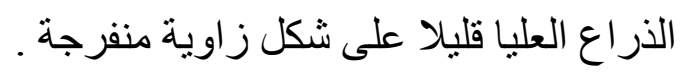
وتتميّز هذه المرحلة بتهيئة الجسم فى وضع متجداوب مرنه، و والتركيز على أن يكون ثقل

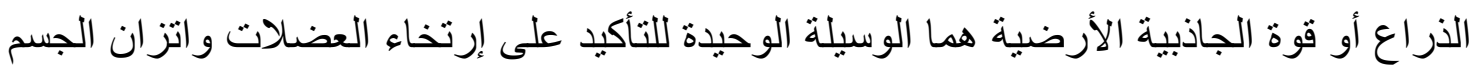
وحرية الحركة أثناء العزف . لجاديه الارفئ. المرحلة الثانية : تنمية القدرة الحسية: المقصود بها إيجاد النغمات عن طريق اللمس ، وتنمية الإحساس بالأبعاد التي تنحصر بين

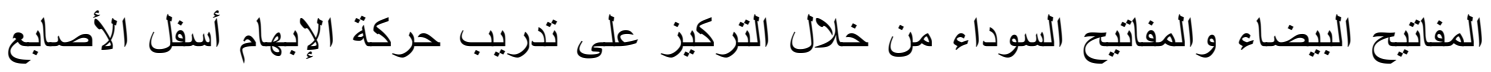

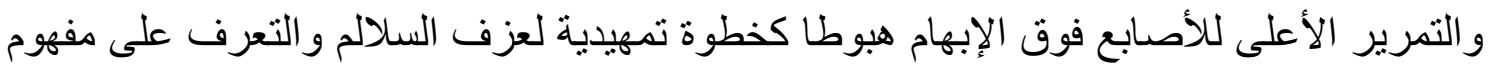

** Karl Leimer : a German music teacher and pianist, has many Books in piano pedagogy, such as Piano Technique, Modern Piano Playing

(AmeSea Database - me -January- April. 2018- 0344) 
الاتجاه الصاعد و الهابط دون النظر إلى لوحة المفاتيح، وتقترح الدراسة استخدام التمرينات التالية

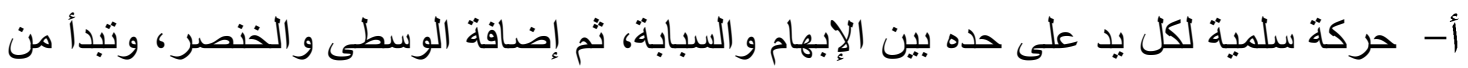

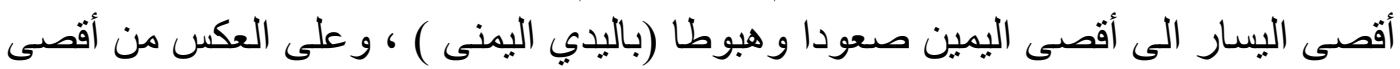

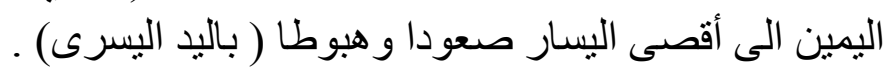

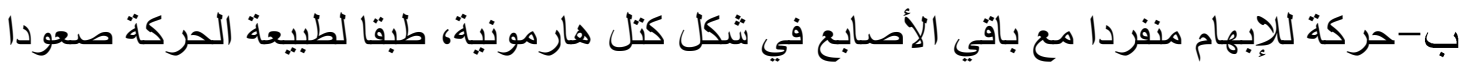

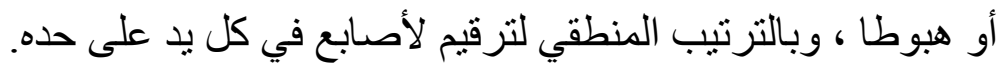

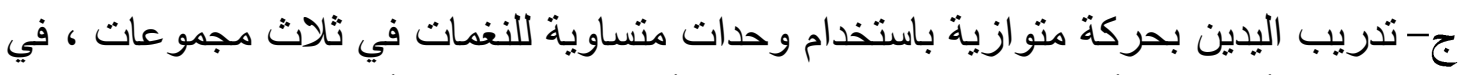

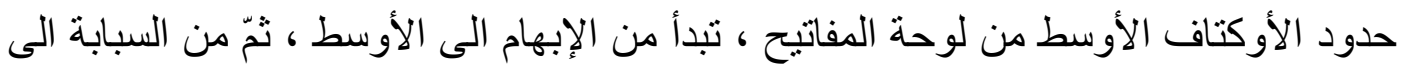

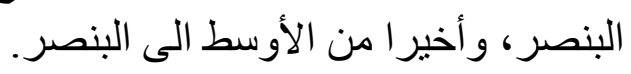
د- التدريب على عزف النغمات السلميه في الإني مساحة أوكتافين أو أكثر باستخدام الحركة الجانبية من الذراع كما حلية الجليساندو.

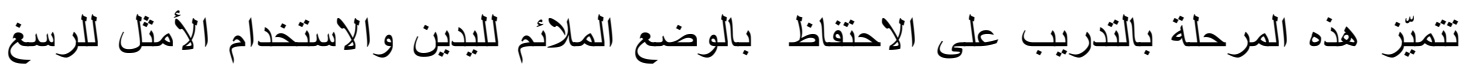

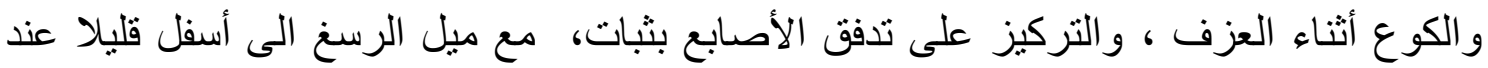

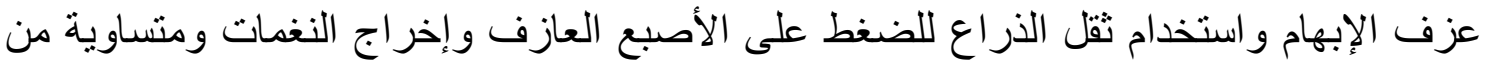

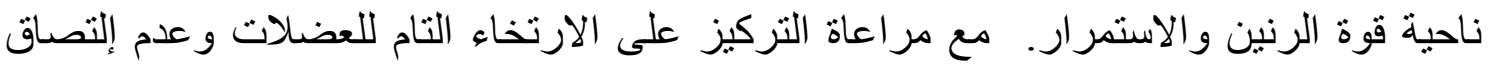

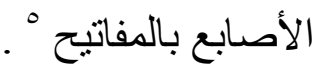

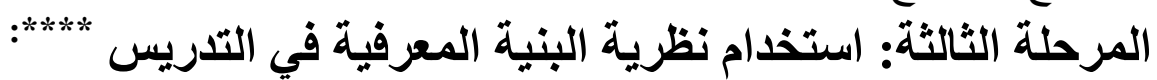

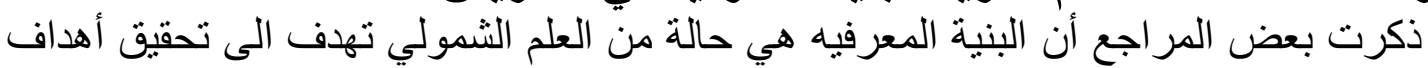

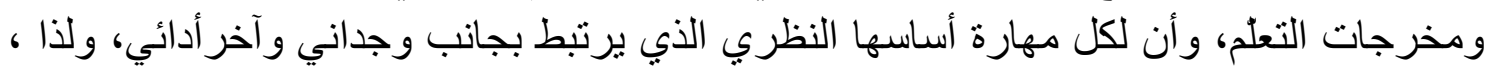

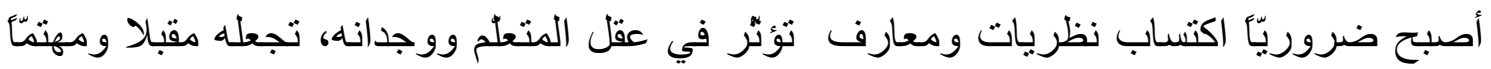

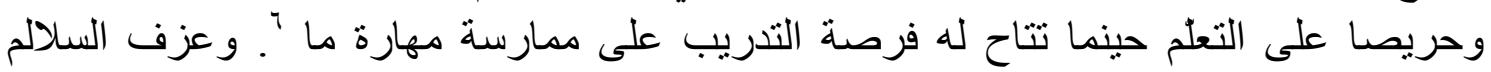

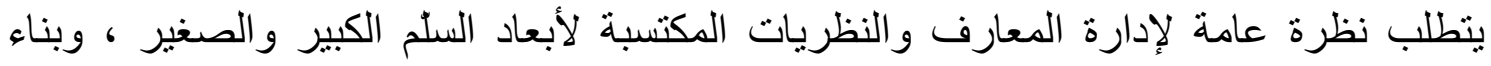

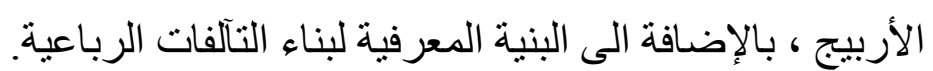

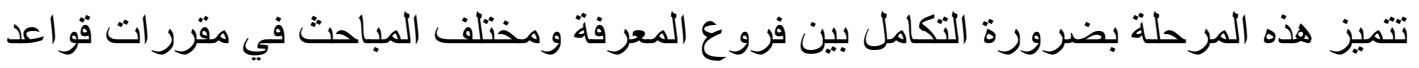

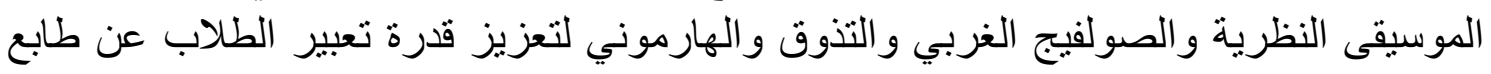
السلم الكبير و السلم الصغير بنو عيه (الهارموني - الميلودي).

كيفية تقويم مهارات أداء السلالم :

ث**** التمرينات المقدّمة من ابتكار الباحثة ونم استخدامها في أبحاث تجريبية داخل وخارج المؤسسة التعليمية ، وقد حققت أهداف التعلم

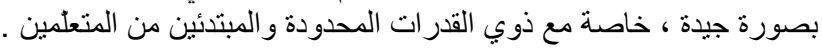
5 Professional Piano Teaching, Volume 2: A Comprehensive Piano Pedagogy Textbook

العزوف استندت الباحثة على المر اجع العلمية في مجال مفهوم البنية المعرفية ،وتم استخدام هذه النظرية في العديد من الحالات مع مر اعاة

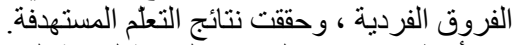

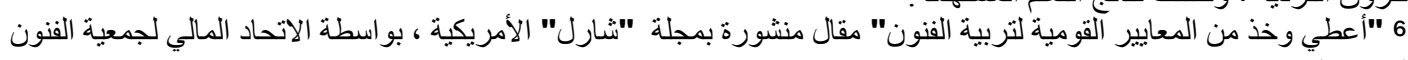

(AmeSea Database - me -January- April. 2018- 0344) القومية التربوية. 
التقويم المبئي: ويقوم على التعارف الثخصي بين الأستاذ و الطالب المبتدئ خاصة الذي يأتي من

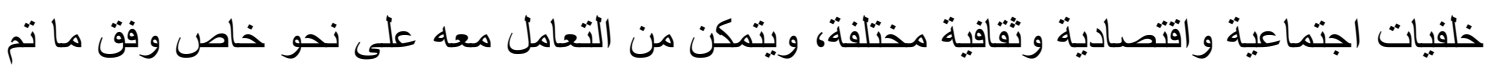
تعرُفه. - التقويم التشخيصي: يتم في بداية العام الدراسي بهدف التعرهف على إمكانات الطلاب

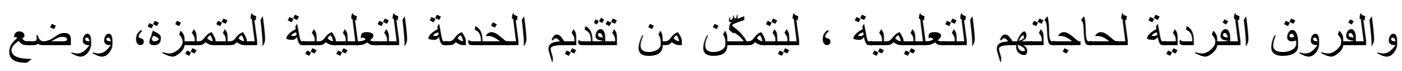
الحلول المناسبة للطلاب الذين يعانون مشكلات معينة في التحصيل خاصة أثناء عزف السلالم

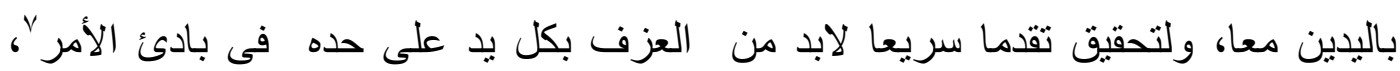

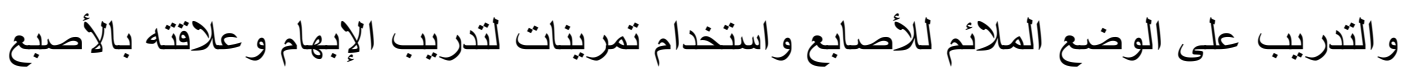

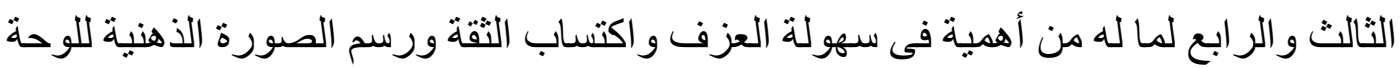
المفاتيح حتى يتمكن المتعلم من الأداء بسهولة ومرونة باليدين معا وبأقل جهد مبذول. - التقويم المستمر( التكويني): يحدث أثناء التدريس من خلال إجراء تقويم مستمرلتوفير

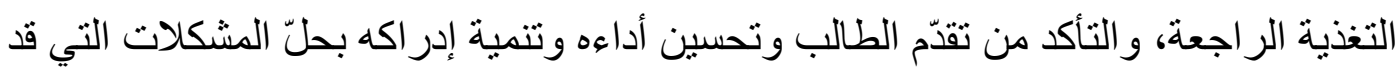

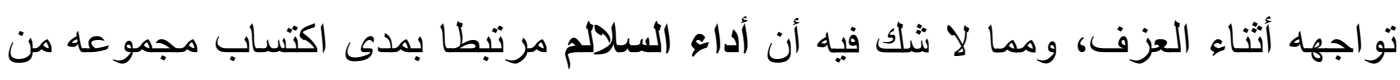

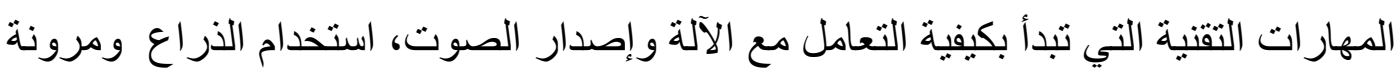
الرسغ ‘. وتلعب الأذن هنا دورا كبير التحقيق مخرجات التعلم المستهافة لأداء جميع بنود محتوى

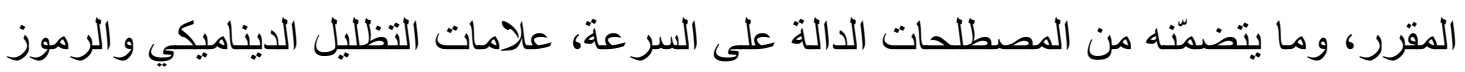
الدالة على تحديد التقسيم العباري و الأداء المفصلي، مصطلحات التعبير الدالة على أسلوب العصر وطابع المؤلفة او الجزء المتناول ه - - التقويم الختامي: من خلال بطاقة أداء متوازن، تسمح بترجمة نواتج التعلم المستهدفة الى الى

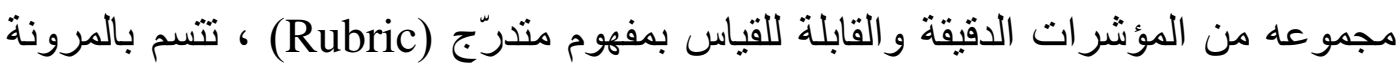
وتناسب الموقف التعليمي ، وتراعي الفروق الفردية لقدر ات الطلاب و أنماط تعلمهم '.

\footnotetext{
7 Professional Piano Teaching,

8 Agay, Denes:" Teaching Piano", Hamilton Printing Company, V.1, New York, 1981.p. 54-55.

9 Randel , D. , Michael : The Harvard Concise Dictionary of Music and Musicians , Harvard College , USA , 1999. P. 506.

10 10نجوى ابو النصر : " توظيف بطاقة أداء إلكترونية لقياس الإباع و التميّز الطلابي في الاختبارات العملية" بحث منشور بالعدد

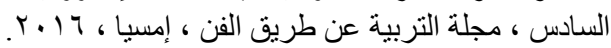

(AmeSea Database - me -January- April. 2018- 0344) 


\begin{tabular}{|c|c|c|c|c|c|}
\hline$\cdot$ & ق & ج & جج & مم & المؤشر ات \\
\hline (iㅔ) & (ly) & (t) (t) & (liv) & (t) (t) & متوازية نغية نغات صحيحة بكلتا اليدين في انسيابية وترابط حركة \\
\hline (네) & (⿻上丨𣥂巾) & (i) & (⿻上丨𣥂巾) & $\frac{(4) 10)}{(1)}$ & بحركة يوكسية. نغمات صحيحة بكلت البدين في انسبابية وترابط \\
\hline (粆) & 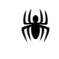 & $\frac{(4)}{(\pi) 11}$ & 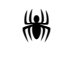 & $\frac{(4)}{(1) 111}$ & يستخلم الترقيم الصحيح للأصابع · \\
\hline (iㅔ) & (颗) & 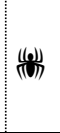 & (踖) & $\frac{(4)}{(1) 111}$ & ; بؤلدي النغعات متساوية في القوة ملتزما بلقة التوازن الإيقاعي ( \\
\hline 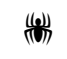 & (vivi) & (t)ili) & 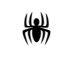 & (歫) & يؤدي اوضاع الأربيج بحركة متو ازية في انسيابية وتر ابط \\
\hline (果) & 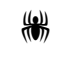 & $\frac{(4)}{(\pi) 11}$ & (踖) & $\frac{(6)}{(111)}$ & يؤلدي الوضع المقرر للأربيج بحركة عكسية في انسيابية وترابط \\
\hline (楎) & (⿻上丨𣥂巾1) & (It) & (⿻ل1) & (tivi) & يحقى أهداف تعليمية تكنيكية متنوعة \\
\hline (果) & 粠) & 紫 & 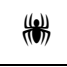 & $\frac{(4)}{(1)}$ & يعزف باستمر ارية وبدون تجزئه أو توقف \\
\hline (颗) & 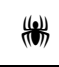 & 政) & (踑) & (觜) & بلتزم بالسرعه الملاعمة للمؤلفات بدحتوى المقرر \\
\hline (井) & 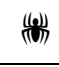 & 歫) & 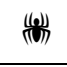 & 政) & يعزف الخط اللحني بوضوح أكثر من المصاحبة \\
\hline 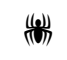 & (⿻上丨𣥂巾) & (鮆) & 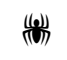 & (毞) & يلتزم بعلامات التظليل الديناميكي والتشكيل الموسيقي المدونة \\
\hline (颗) & (viti) & (1) & (粫) & 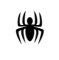 & يغزف لحن في اليل البيسى والمصاحبة في البي البينس \\
\hline (果) & (⿻山木丶) & (ivi) & 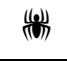 & (10i1) & بنظر الحى المدونـه أثثاء الأداء \\
\hline (颗) & (米) & (步) & 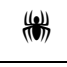 & 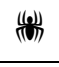 & يعزف ملتزما بالسكتات مع استمرارية الأداء والاحتفاظ بالزمن \\
\hline (颗) & 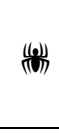 & $\left.\frac{(4)}{(\pi) 11}\right)$ & (踖) & 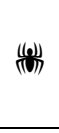 & يعزف بالمنطقة الصوتية الصحيحه مع مراعاة الاتقال بين المناطق \\
\hline (粆) & 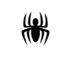 & (tiv) & (⿻山木丶) & (紫) & يؤلدي مصطلحات تغيير السرعة \\
\hline 粠) & 踖) & $\frac{(4)}{(1)}$ & 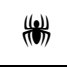 & 步监 & يؤدي الرباط اللحني والزمني ملتزما ببداية العبارات ونهاياتها. \\
\hline (果) & (veli) & (ivi) & 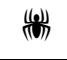 & $\frac{(4) 111}{(\pi)}$ & يغزف اللدن ملتزما بتأخبر النبر (tempo Rubato) \\
\hline (耤) & (临) & (ivi) & (此) & 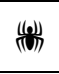 & يغزف تآلفات أو أربيجات في اللحن الأساسي والمصاحبة. \\
\hline 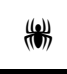 & 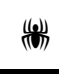 & 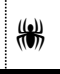 & (⿻山木丶) & 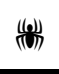 & يؤدي الأقواس اللحنية والزمنية ملتزما بدقة الوحدة الزمنية \\
\hline
\end{tabular}

(AmeSea Database - me -January- April. 2018- 0344) 
'. العمل على تطوير محتوى مقررات البيانو لمرحلة البكالوريوس ، و إعادة ترتيب عنصر

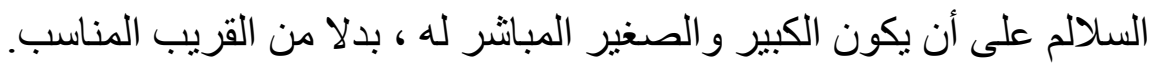

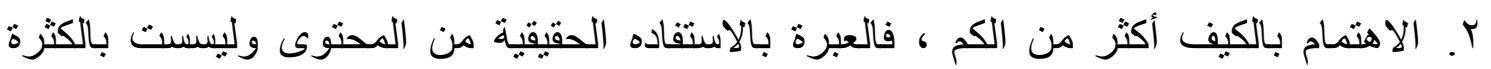

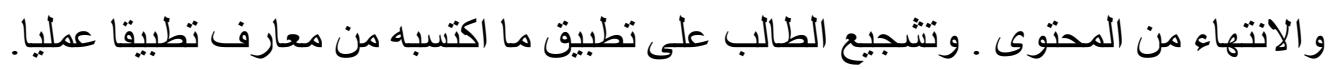

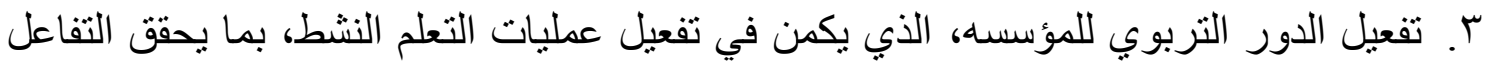
بين الأستاذ و الطالب وجعالها بيئة جاذبة للطلبة. ع. تطوير دور أستاذ المقرر من مجرد الناقل الوحيد للمعلومات إلى الطى كونه ميسرأ لبيئة التعلم ومصمما للمو اقف التعليمية. ○. نشر ثقافة التقويم الذاتي لدى أفر اد المؤسسة التعليمية. وجعل التقويم عملية إنتاجية تثاركيه بين استاذ المقرر و الطالب لتنمية اتجاهاته الإيجابية.

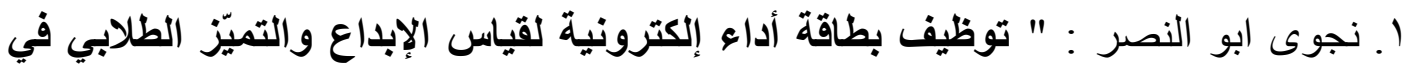

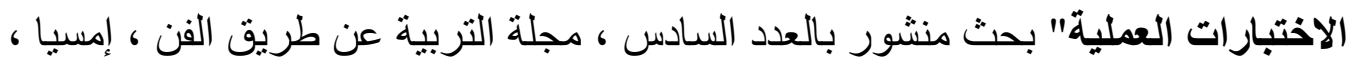
r. 17 r. اللقاني ، أحمد حسين وآخرون :" مناهج التعليم بين العلم والواقع" القاهرة : عالم الكتب ، . r. عودة، أحمد : القياس والتقويم في العملية التدريسية، دار الأمل للنشر والتوزيع،

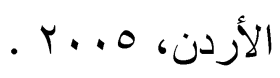

Agay, Denes:" Teaching Piano", Hamilton Printing Company, V.1, New . ع York, 1981.

Jacobson, Jeanine M: Professional Piano Teaching, Comprehensive .๑ Piano Pedagogy Textbook, Volume 2: A, Alfred Music, 2015. Randel, D., Michael: The Harvard Concise Dictionary of Music and 7 Musicians, Harvard College, USA, 1999.

(AmeSea Database - me -January- April. 2018- 0344) 